\title{
A VOZ HÍBRIDA DE GLORIA ANZALDÚA: DO MARGINAL À NOVA MESTIÇA CHICANA
}

\author{
Ana Cristina dos Santos ${ }^{1}$
}

\begin{abstract}
Resumo: Este trabalho discute a constante reformulação e negociação identitária que aflora dos sujeitos femininos emergentes dos entre-lugares na literatura escrita por mulheres, especificamente as chicanas, tendo como base o livro Boderlands/La frontera - The new mestiza (1987), da escritora chicana Gloria Anzaldúa. O texto de Anzaldúa propõe, através de questões que ultrapassam as noções de gênero e aliam-se às questões de raça, etnia, orientação sexual e classe social, uma nova identidade para o sujeito feminino marginalizado que nasceu e viveu no espaço móvel, polifônico e híbrido da fronteira MéxicoEstados Unidos.
\end{abstract}

Palavras-Chave: Literatura chicana, Escrita feminina, Hibridismo cultural, Identidade, Gloria Anzaldúa.

Resumen: Este trabajo discute la constante reformulación y negociación de la identidad que aflora de los sujetos femeninos emergentes de los entre-lugares en la literatura escrita por mujeres, específicamente las chicanas, teniendo como base el libro Boderlands/La frontera - The new mestiza (1987), de la escritora chicana Gloria Anzaldúa. El texto de Anzaldúa propone, a través de cuestiones que ultrapasan las nociones de género y se alían a las cuestiones de raza, etnia, orientación sexual y clase social, una nueva identidad para el sujeto femenino marginalizado que nació y vivió en el espacio móvil, polifónico e híbrido de la frontera México-Estados Unidos.

Palabras-Clave: Literatura chicana, Escrita feminina, Hibridismo cultural, Identidad, Gloria Anzaldúa.

1 Professora Adjunta do Departamento de Letras Neolatinas (Literaturas Hispânicas) e do Programa de PósGraduação em Teoria da Literatura e Literatura Comparada do Instituto de Letras da Universidade do Estado do Rio de Janeiro (UERJ). Doutora em Letras Neolatinas pela UFRJ. Membro do GT ANPOLL "Vertentes do Insólito Ficcional”. Endereço eletrônico: anacriss@terra.com.br. 
Because I, a mestiza, continually walk out o fone culture and into another,

Because I am in all cultures at the same time, alma entre dos mundos, tres, cuatro, me zumba la cabeza con lo contradictorio. Estoy norteada por todas las voces que me hablan Simultáneamente. (ANZALDÚA, Gloria, 2007, p. 99).

\section{INTRODUÇÃO}

A partir dos anos 60 do século XX, como consequência da expansão imperial e da homogeneização social, basicamente no eixo euro-norte-americano, começaram a aparecer vozes dissonantes do pensamento hegemônico. Essas vozes, marginalizadas pelo poder não só em relação a sua posição na divisão social do trabalho e no gozo dos seus direitos, mas também aos seus valores culturais, reivindicavam as características que distinguiam suas subjetividades dentro do território em que habitavam. Denunciavam o caráter ontológico do discurso identitário homogeneizante e mostravam a falência das verdades absolutas: essas eram construções discursivas que serviam a interesses culturais predeterminados e, por conseguinte, eram passíveis de desconstrução e de reconstrução.

Entre as vozes periféricas, a feminina foi a primeira a romper com o poder dominante. Ao revelar a utilização de um discurso que não lhe representava e a necessidade de analisar as personagens femininas sob a sua própria visão. Com isso, rejeitaram a identidade feminina construída, já que representavam uma voz proveniente do discurso masculino ou do mainstream feminino. A partir dessa conscientização, o discurso periférico feminino rompeu com o discurso construído sob a visão do Outro, para construir, através das suas experiências, uma nova subjetividade para o sujeito que nasceu e viveu nas margens.

Desde 1980, as escritoras chicanas ${ }^{2}$ nos Estados Unidos inserem-se nessas discussões. É nessa época que se consolida a literatura chicana e, especificamente, a de autoria feminina. Os textos aparecem como uma forma de legitimização da identidade racial e cultural da mulher

2 Chicano(a) é o(a) cidadão(ã) dos Estados Unidos pertencente à minoria de origem mexicana ali existente, oriundos de várias gerações dos antepassados, que foram obrigados a aceitar a cidadania americana quando as suas terras foram conquistadas durante a expansão nacional do EUA no século XIX (SKAR, 2001, p. 9-10). 
Pontos de Interrogação, v. 3, n. 1, jan./jul. 2013

Revista do Programa de Pós-Graduação em Crítica Cultural

Universidade do Estado da Bahia (UNEB), Campus II - Alagoinhas - BA

mestiça e chicana. Para tanto, problematizam as relações assimétricas entre os gêneros, as relações de poder entre as culturas do maisntream e as de fronteira e a contínua negociação da identidade híbrida e fragmentária do sujeito em constante movimento que vive na fronteira México-Estados Unidos. Também enfatizam as diferenças étnicas, raciais, sexuais e classistas que as diferenciam das mulheres anglo-europeias e não aceitam que elas falem em seu nome, sem distingui-las como um grupo particular.

Nesse artigo, nosso interesse é justamente discutir a reformulação e negociação identitária presente nos sujeitos femininos emergentes dos entre-lugares na literatura escrita por mulheres, especificamente na literatura chicana. Para ilustrar a discussão proposta, utilizamos o livro Boderlands/La frontera - The new mestiza, publicado em 1987, pela escritora chicana Gloria Anzaldúa. Nele, a autora faz uma revisão da história de sua comunidade, vista de uma perspectiva feminina e homossexual. As reflexões apresentadas por ela na obra contribuem para desarticular as categorias conceituais e organizacionais de gênero, orientação sexual, etnia, raça e nacionalidade presentes em qualquer pretensão à identidade no mundo moderno. Ao mesmo tempo em que o texto desconstrói essas categorias, ele favorece a elaboração de novas estratégias de subjetividades que reconstroem novos signos de identidade para o sujeito feminino das zonas fronteiriças.

Em Boderlands/La frontera, Anzaldúa enfoca o surgimento de uma nova subjetividade que não é branca, nem índia, nem hispânica, mas mestiça, nascida em um contexto cultural e social específico, o "entre lugar” da cultura chicana: a fronteira entre o México e os Estados Unidos. Através da ressignificação dos conceitos relacionados às questões de gênero, etnia e orientação sexual disseminados pelo poder hegemônico, Anzaldúa cria um discurso que aponta para a legitimização da voz triplamente diferente - mulher, mestiça e lésbica: "Nos anos oitenta, já tinha outra maneira de nomear-me. Não era mais chicana, também era mulher de cor, feminista, e também lésbica — queer [...]”3 (JOYSMITH, 2004, p. 222-3).

Seu texto engloba, sob os paradigmas da contemporaneidade, tanto as fronteiras físicas quanto as invisíveis que controlam o sujeito na sociedade para diluir os limites referenciais de centro e periferia, local e global, puro e impuro, colonizado e colonizador. Cria um espaço

3 Tradução livre da autora do trabalho. 
intersticial, expandido e ex-cêntrico de aquisição de poder que invalida quaisquer formas de repressão imposta pelo discurso hegemônico. Ao mesmo tempo, explora as ambivalências de sua mestiçagem produzida séculos antes pela conquista espanhola e lembrada a cada instante como elemento de inferioridade pelas culturas dominantes e ao examinar sentido de "mestiça”, acaba também por mergulhar mais fundo no próprio significado da noção de fronteira.

Se o seu desejo é eliminar as fronteiras que delimitam o espaço e a subjetividade chicana, então, nada mais coerente que sua narrativa também perca as limitações de gênero impostas pelo discurso canônico. Cria em Boderlands/La frontera um texto híbrido que reúne ensaios, teoria literária, conto, poemas, lendas, tradições, autobiografia e testemunho. Com a negação dos limites impostos pela ideologia dominante, a autora desafia os padrões impostos à identidade indiferenciada dos chicanos como o “Outro”, inferior à identidade pura e hegemônica dos estadunidenses e dos mexicanos, especificamente da mulher subalterna, a mestiça chicana, que opta por uma terceira opção sexual. Essa atitude cria uma obra capaz de “[..] articular, (re)nomear, traçar mapas não cartografados; além de forjar um espaço a partir do qual e de onde as mulheres de cor possam se autoinventar em uma nação que as mantém às margens de questões sociopolíticas, econômicas, raciais/étnicas e literárias” (JOYSMITH, 2004, p. 220).

Porém, antes de iniciar a análise da obra de Anzaldúa, é essencial abordar a relação entre a escrita feminina e as questões de gênero, poder e recontextualização de uma nova subjetividade para compreender os mecanismos utilizados por Anzaldúa para desconstruir a identidade hegemônica da mestiça chicana e reconstruir uma identidade diferente e legitimadora para essa mulher. Abordar tal relação é necessário porque a escrita chicana de Anzaldúa tem como pilar central a construção de uma nova subjetividade que encara o seu espaço tanto pela ótica da alteridade de gênero — a aposição masculino/feminino; quanto pela alteridade feminina — mulher branca $\mathrm{x}$ de cor.

\section{MULHER E PODER: UMA RELAÇÃO CONSTRUÍDA}

O advento dos discursos feministas aconteceu na década de setenta do século passado, em meio a contestações políticas e sociais mais amplas ocorridas em diversas sociedades ocidentais. Esses discursos, baseados em discursos desconstrutivistas, consideravam fundamental 
Pontos de Interrogação, v. 3, n. 1, jan./jul. 2013

Revista do Programa de Pós-Graduação em Crítica Cultural

Universidade do Estado da Bahia (UNEB), Campus II - Alagoinhas - BA

a revisão dos códigos culturais e sociais nos quais as sociedades ocidentais se organizavam. Tinham como objetivo expor que as diferenças entre os sexos masculino e feminino eram oriundas de uma construção cultural: o papel ocupado pela mulher na sociedade e a sua não valorização eram produtos da construção do olhar masculino sobre elas. Para defender essa tese, a crítica feminista recorreu aos estudos de gênero com a finalidade de revisar e desconstruir conceitos seculares considerados indiscutíveis, tais como poder, hierarquia, submissão e os próprios termos feminino e masculino, como nos esclarece Bila Sorj (1992, p. 15-6):

Diferente do sexo, o gênero é um produto social, aprendido, representado, institucionalizado e transmitido ao longo das gerações. E, segundo, envolve a noção de que o poder é distribuído de maneira desigual entre os sexos, cabendo às mulheres uma posição subalterna na organização da vida social.

Através da teoria de gênero, a crítica feminina pôde compreender que os esquemas representacionais e a subjugação a que foi imposta a mulher durante séculos possuíam uma relação intrínseca com a noção do poder. O mainstream masculino que estava no centro possuía e controlava o poder (em todas as suas esferas) e tinha o direito de representar (segundo o seu próprio “olhar”) os “outros” que estavam à margem desse poder. Ao fazer essa inter-relação, a crítica feminina percebeu que as representações femininas impostas por determinadas épocas eram disseminadas por práticas culturais e discursivas e estavam relacionadas às pressões políticas, econômicas e sociais que transmitiam atitudes, qualidades e identidades como inerentes à natureza de homens e mulheres. Dessa forma, a discussão teórica sobre gênero enfatizou ideias que, enraizadas durante séculos, tomavam por natural o que era produto cultural: uma relação hierárquica na qual o masculino se projetava como princípio superior e, assim dominante, frente ao feminino. O paralelismo entre a noção de gênero e identidade tornou-se, então, tema capital no processo de autoconhecimento das sociedades modernas, como afirma Mary Louise Pratt (apud CORBATTA, 2002, p. 14):

O debate sobre o gênero discutido por homens e mulheres, através do espectro ideológico e social, e através de toda a história da América Latina, deveria ter um lugar central na história intelectual do continente, o mesmo sobre o debate sobre a identidade. Deveria ser reconhecido como central no processo de autocriação e de autocompreensão da sociedade ${ }^{4}$.

4 Tradução livre da autora do trabalho. 
A discussão ressaltou como a cultura hegemônica patriarcal se apropriou das diferenças existentes entre os gêneros para manter o status quo e justificar as desigualdades e a posição de subordinação ocupada pelas mulheres em diferentes situações e culturas. Essa comprovação fez emergir as relações de poder e dominação da cultura falocêntrica, delimitando uma fronteira entre o universo social feminino e o masculino que promoviam o feminino à submissão social e o seu afastamento do mundo público, como se as mulheres não pudessem participar desse universo de poder. Marcava-se, assim, o mundo privado, o da subjugação, como feminino e o público, o do poder, como masculino. Essa diferença corroborou durante décadas para a ideologia patriarcal de segregação das mulheres das posições de autoridade na sociedade.

Contudo, segundo Chanter (2011, p. 16), os estudos de gênero não foram importantes somente porque lutaram contra o sexismo imperante nas sociedades. Para ela, esses debates ressaltaram que o feminino foi uma luta focada também no racismo, no clascismo e no heterossexismo. Assim, a partir de 1980, ao incorporar o estudo das relações de gênero ao contexto social, a diferença deslocou-se do plano de uma dicotomia apenas de gênero (a distinção entre masculino e feminino) ${ }^{5}$, para a incorporação dos estudos culturais e etnográficos. Iniciou-se, assim, o questionamento do termo "feminino" a partir das diferenças existentes também entre as mulheres e no interior das mulheres. Esses estudos afirmavam que não se podia categorizar o feminino sem enfocar a "diferença na diferença”; ou seja, as várias camadas de subordinação existentes no feminino e não reduzidas unicamente à questão de gênero, mas que englobavam também um falso universalismo do termo, cujos privilégios condiziam somente com uma ideologia feminista branca, urbana, de classe média e heterossexual:

\begin{abstract}
A mulher de cor iniciante é invisível no mundo dominante dos homens brancos e no mundo feminista das mulheres brancas, apesar de que, neste último, isto esteja gradualmente mudando. A lésbica de cor não é somente invisível, ela não existe. Nosso discurso também não é ouvido. Nós falamos em línguas, como os proscritos e os loucos (ANZALDÚA, 2000, p. 229)
\end{abstract}

A partir da incorporação da noção de diferença "entre" as próprias mulheres, Butler (2010, p. 18) destaca que o sujeito feminino não pode ser compreendido em termos estáveis e permanentes. Para ela, a discussão revelou a existência de uma heterogeneidade e fez com que

5 Segundo Teresa Ebert (1999, p. 217), “A organização de oposições binárias é hierárquica e patriarcal (falocêntrica)". Tradução livre da autora do trabalho. 
Pontos de Interrogação, v. 3, n. 1, jan./jul. 2013

Revista do Programa de Pós-Graduação em Crítica Cultural

Universidade do Estado da Bahia (UNEB), Campus II - Alagoinhas - BA

fosse impossível utilizar o termo "mulher” sem adjetivá-lo: mulher branca, negra, latina, homossexual etc. Desse modo, a definição e o emprego do termo "feminino" ultrapassaram as questões de gênero e aliaram-se às demais questões de identidades discursivamente constituídas (etnia, raça, sexo), requerendo uma redefinição do modelo do discurso teórico básico da ideologia feminina em relação aos privilégios de uma identidade sobre a outra. A partir de então, foi necessário que o discurso universalista feminino começasse a ouvir as diversas vozes femininas marginalizadas em seus discursos homogeneizantes. Foi necessário que o feminino se deslocasse também do centro e pensasse em si mesmo também a partir das margens.

Essa reflexão ressaltou que o sujeito feminino também se dividia em sujeito do centro de poder e sujeito das margens. Enquanto mulher dividia as mesmas condições históricas de opressão e marginalização inerentes ao gênero, mas divergia enquanto situações particulares e fatores culturais, tais como nacionalidade, religião, língua, tradições, modos de vidas, concepções de mundo e níveis de opressão. A identidade feminina passou a ser construída não apenas na oposição binária feminino/masculino, mas também através das diferenças existentes entre as relações de poder articuladas por etnia, sexualidade, classe, nacionalidade, linguagem e religiosidade. Assim, ampliaram-se os estudos sobre a questão identitária feminina. Tornouse necessário saber de que maneira se constituía o sujeito que sofria relações de poder e aquele que exercia essas relações, não só em relação à oposição feminino x masculino, mas também em oposição feminino x feminino. Desse modo, o foco da discussão teórica se voltou também para toda e qualquer relação de poder que estabelecia fatores de identidade, tanto pessoal quanto coletiva. Com isso, relacionou-se a condição feminina às condições de opressão de todo e qualquer sujeito submetido à dominação e à marginalização social.

Por esse motivo, a crítica feminista associou a discussão sobre opressão feminina às práticas discursivas, conscientizando-se de que o conceito de identidade que definia o sujeito “mulher” era também uma construção linguística e contextualizada historicamente e, portanto, passível de questionamento. Essa crítica identificou a linguagem o principal instrumento utilizado pelo poder falocêntrico para viabilizar as relações de poder, já que ela é reguladora da função do sujeito nas sociedades. Para Velasco Marín (2007, p. 551 et seq.), a linguagem sempre foi utilizada como instrumento de dominação e opressão pela cultura hegemônica. Segundo a teórica, houve a necessidade de os grupos minoritários mostrarem a arbitrariedade 
da linguagem como mecanismo de força, capaz de estruturar o olhar do Outro através de um “imaginário branco", para que se revelasse a opressão a que esses grupos eram submetidos.

Acrescenta que o feminino, com o intuito de construir uma identidade própria, desvelou a máscara da linguagem neutra que lhes impunham uma identidade outra ao relacionar a escrita com o conhecimento e o poder e mostrou a necessidade da subversão dos sistemas masculinos entendidos como perspectiva universal de representação. Dessa forma, a questão da construção identitária ultrapassa a oposição binária de categorias (como o feminino e o masculino, brancos e negros) ao questionar um sistema de valores instituído pelos grupos detentores do poder, legitimador de um discurso dominante e narcisista que não reconhece a diferença.

Essa constatação levou às minorias de poder - entre elas as mulheres negras, as indígenas, as pobres e as homossexuais - a encontrarem um modo de se fazerem visíveis, de erguerem as suas vozes para saírem da marginalização imposta pela hegemonia dominante branca e de classe média, de clamarem por suas identidades e, assim, obterem o reconhecimento sociocultural de suas diferenças. Sob essa ótica, compreende-se a necessidade atual de cada grupo minoritário construir uma identidade própria, pois como afirmam Figueiredo e Noronha (2005, p. 191):

[...] uma identidade não é elaborada isoladamente, mas antes negociada pelo indivíduo durante toda a vida, se depreende daí a importância do reconhecimento nessa construção. Entende-se, desse modo, porque a questão identitária só interessa e só é reivindicada por aqueles que não são reconhecidos por seus interlocutores. (Grifo nosso).

\section{DUPLA MARGINALIZAÇÃO}

Discutir o problema do feminismo na cultura hispânica obriga, além de reconhecer o papel histórico desempenhado pelas sociedades patriarcais (brancas ou não) sobre a população em geral e as mulheres em particular, a analisar também as questões relacionadas às discriminações potencializadas em termos de etnia e cultura. A exclusão e invisibilidade dos grupos minoritários não dependem apenas do fato de pertencerem a este ou aquele gênero, mas fundamentalmente de pertencerem a esta ou aquela etnia.

Na medida em que a marca da etnicidade foi construída pelas diferenças impostas pelos conquistadores (o colonizador branco e europeu rejeitou o que não era espelho) e que nela 
Pontos de Interrogação, v. 3, n. 1, jan./jul. 2013

Revista do Programa de Pós-Graduação em Crítica Cultural

Universidade do Estado da Bahia (UNEB), Campus II - Alagoinhas - BA

subjaz a noção de poder, não é de surpreender que as escritoras latino-americanas, pertencentes aos subgrupos étnicos, sejam as que exploram de modo mais consistente a noção de hibridez/mestiçagem étnica. Suas obras enfatizam essa dupla colonização: sujeito mulher e mestiço, portanto, marginalizado. Temas inseparáveis do universo social em que vivem. Por isso, muitas das autoras se engajam nas questões político-sociais, unindo discurso literário e militância política em seu próprio país ou fora dele. O objetivo é revelar que os elementos geradores de choques sociais, étnicos, sexuais são construtos sociais e como tais, podem e devem ser denunciados e reconstruídos para subverter a ordem estabelecida pelos centros hegemônicos de poder.

Ao fazerem isso, as escritoras da região apontam para a compreensão das fontes de suas pertenças múltiplas, a necessidade de nomeá-las, de articular suas raízes e explicar o processo de transculturação que abarca todo o hemisfério. Assim, contribuem para revisar a história e questionar a opressão imposta pela cultura dominante. Esse processo de redescobrimento e conscientização revela que a identidade feminina desses grupos minoritários se revisa e se reconstrói nas fronteiras entre o hegemônico e o mestiço, no encontro e fusão das heranças pré-hispânicas, negra e branca, nas memórias esquecidas que contribuem para a transformação e a construção dos entre-lugares das heterogeneidades culturais e sociais que marcam a região. Esse processo de conscientização de uma subjetividade outra expõe uma identidade mestiça que não é nem branca, nem negra, nem índia, mas que se constrói nos seus interstícios.

Desse modo, a identidade mestiça se relaciona não só com as questões raciais e étnicas advindas dos processos de colonização da América Hispânica, mas também com os encontros resultantes dos espaços favoráveis ao entrecruzamento de culturas: as zonas fronteiriças, principalmente a fronteira México-Estados Unidos. Lugar de deslocamento constante, esse espaço móvel, polifônico, feito de incessantes travessias tanto internas quanto externas é para Burke (2010, p. 73) “[...] não apenas locais de encontro, mas também sobreposições ou interseções entre culturas, nas quais o que começa como uma mistura acaba se transformando na criação de algo novo, diferente”. Esse “algo novo” designado por Burke é a fusão de elementos culturais que "atravessam” o sujeito da fronteira e leva ao nascimento de uma etnicidade híbrida que nasce e vive nesse espaço intersticial: o chicano. 
Para Torres (2001, p. 29) a fronteira “é a grande metáfora para o lugar ocupado pelo(a) chicano(a), mesmo quando ele não reside nos cerca de $4.200 \mathrm{~km}$ que os EUA compartilham com o México”. Ela é o lugar de enunciação de Borderlands/La Frontera. The New Mestiza (2007), de Anzaldúa. É nesse espaço transculturador que a autora explora, revisa e redefine as fronteiras externas e internas do sujeito feminino mestiço, rejeitando o lugar marginalizado que a cultura hegemônica lhe destinou.

\title{
3 IDENTIDADE FRONTEIRIÇA CONTRA-HEGEMÔNICA: A NOVA MESTIÇA
}

A obra de Anzaldúa propõe uma reflexão sobre os hibridismos resultantes dos diversos processos históricos culturais da região de fronteira entre o México e os Estados Unidos e as relações identitárias de uma nova raça - a mestiça — que se constroem e se reconstroem nesse espaço polifônico:

\begin{abstract}
Nascida em uma cultura, posicionada entre duas culturas, estendendo-se sobre todas as três culturas e seus sistemas de valores, a mestiça enfrenta uma luta de carne, uma luta de fronteiras, uma guerra interior. Como todas as pessoas, percebemos a versão da realidade que nossa cultura comunica. Como outros/as que vivem em mais de uma cultura, recebemos mensagens múltiplas, muitas vezes contrárias. $\mathrm{O}$ encontro de duas estruturas referenciais consistentes, mas geralmente incompatíveis, causa um choque, uma colisão cultural ${ }^{6}$ (ANZALDÚA, 2007, p. 100. Grifo da autora).
\end{abstract}

O enunciador entrecruza a questão da mestiçagem racial e cultural com a do feminino, abordando as principais formas de subjugação da cultura branca dominante (seja ela mexicana ou estadunidense, masculina ou feminina) sob a cultura chicana periférica. Com isso, relaciona a questão do gênero com a da raça, etnia e orientação sexual:

Comecei a pensar: Sim, sou chicana, mas isso não define quem eu sou. Sim, sou mulher, mas isso também não me define. Sim, sou lésbica, mas isso não define tudo que sou. Sim, venho da classe proletária, mas não sou mais da classe proletária. Sim, venho de uma mestiçagem, mas quais são as partes dessa mestiçagem que se tornam privilegiadas? Só a parte espanhola, não a indígena ou negra. Comecei a pensar em termos de consciência mestiça. O que acontece com gente como eu que está ali no entre-lugar de todas essas categorias diferentes? O que é que isso faz com nossos conceitos de nacionalismo, de raça, de etnia, e mesmo de gênero? Eu estava tentando articular e criar uma teoria de existência nas fronteiras. [...] Eu precisava, por conta própria, achar algum outro termo que pudesse descrever um nacionalismo mais poroso, aberto a outras categorias de identidade (ANZALDÚA apud COSTA; ÁVILA, 2005, p. 692).

6 Todas as traduções em português do texto de Anzaldúa utilizado são traduções livres da autora do trabalho. O texto em itálico encontra-se no original em língua espanhola e o sem itálico em língua inglesa. 
Pontos de Interrogação, v. 3, n. 1, jan./jul. 2013

Revista do Programa de Pós-Graduação em Crítica Cultural

Universidade do Estado da Bahia (UNEB), Campus II - Alagoinhas - BA

A partir desse questionamento, a autora desconstrói as representações tradicionais forjadas pela cultura hegemônica anglo-americana e mexicana para autorrepresentar o sujeito feminino chicano, segundo o próprio “olhar” de uma mulher chicana. Seu objetivo é fortalecer a identidade mestiça que aflora da fusão de sua própria cultura, a mexicana, com a do dominador. Identidade marginalizada pelo poder dominante e, portanto, excluída das relações de poder. Sua estratégia inclui a ressignificação do vocábulo mestiço e de uma contraetnia, a mestiça. Etnia não existente na classificação racial estadunidense ${ }^{7}$ e menosprezada na cultura mexicana, cuja origem possui uma referência pejorativa, uma vez que os conquistadores espanhóis (e também os portugueses), com a ideologia da pureza do sangue, consideravam o termo como sinônimo de bastardo.

Nesse sentido, a voz narrativa, a través de uma linguagem híbrida que mistura o inglês, o espanhol, o spanglish e o nahuatl ${ }^{8}$, busca uma etnia singular e diferenciadora dentro da cultura dominante que a vê como a "outra”. Essa busca étnica, segundo Hall (2005, p. 86) é necessária para essa nova identidade não ser tratada como “a mesma coisa”, ou seja, idêntica às outras identidades que se contrastam com a hegemônica. A narradora não pretende que essa etnia mestiça seja comparada à latina ou à hispânica, mas que seja vista pelo poder hegemônica como uma identidade com características próprias. Desse modo, o objetivo de Anzaldúa ao construir essa identidade singular é fazer que a cultura branca dominante a diferencie das outras identidades latino-americanas que circulam pelo espaço estadunidense.

No processo de construção identitária feminina mestiça, Anzaldúa parte da história dos chicanos em geral, de sua identidade híbrida para, então, particularizar a condição de opressão da mulher chicana. Como fato histórico, ressalta a hibridez intrínseca do povo chicano oriunda da falta de pertencimento desse grupo social. Eles foram considerados estrangeiros em suas próprias terras, quando os Estados Unidos se apropriaram do território ao norte do México, por conta da assinatura do Tratado Guadalupe-Hidalgo, em 1848. Acrescenta que o Tratado não dividiu somente as terras, mas criou, a partir da divisão, dois polos dicotômicos carregados de valores difundidos pelo poder branco e hegemônico, nos quais o polo positivo era o

\footnotetext{
7 A classificação racial dos Estados Unidos só engloba o eixo preto/branco (cf. TORRES, 2001, p. 46).

8 Língua falada pelos indígenas astecas na época do descobrimento do México. O idioma continua a ser utilizado até os dias de hoje na cultura mexicana.
} 
estadunidense, branco e de classe média e o negativo era o mexicano, pele de cor (moreno) e pobre. Entre esses dois polos, surgiu uma minoria étnica, os chicanos, que foi excluída e/ou subjugada tanto pela cultura dominante anglo-americana, quanto pela mexicana periférica:

No mundo gringo, o chicano sofre de uma humildade e de uma autonegação excessivas, vergonha de si e autodepreciação. Entre os latinos, ele sofre de uma sensação de inadequação linguística e seu consequente desconforto; com os índios americanos, ele sofre de uma amnésia racial que ignora nosso sangue comum, e de culpa, porque a sua parte espanhola tomou suas terras e os oprimiu. Ele tem uma hubris compensatória excessiva quando está entre os mexicanos do outro lado. Encobre um sentimento profundo de vergonha racial (ANZALDÚA, 2007, p. 105. Grifo da autora)

O fato de a cultura chicana não pertencer a nenhum dos dois países, de existir "flutuando” entre os dois polos culturais, em um processo de hibridez múltipla, faz dessa minoria, duplamente desterritorializada, um grupo em constante deslocamento entre as fronteiras, em busca de uma terceira margem, de um espaço seu, no qual enraíze a identidade construída. Anzaldúa utiliza o termo nahuatl nepantilismo para referir-se a esse entre-lugar próprio da cultura chicana. Esse espaço cultural próprio do chicano demanda outras formas de conhecer e sentir a realidade inerente a sua própria etnia. Desse modo, em um movimento contínuo de des-contextualização e re-contextualização cultural, o sujeito chicano retira elementos das culturas com as quais tem contato e modifica-os para encaixá-los na nova cultura que se forma nesse entre-lugar:

Em um estado constante de nepantilismo mental, uma palavra asteca que significa partido ao meio, a mestiça é um produto da transferência de valores culturais e espirituais de um grupo para outro. Ser tricultural, monolíngue, bilíngue, ou multilíngue, falando um patois, e em um estado de transição constante, a mestiça se depara com o dilema das raças híbridas: a que coletividade pertence a filha de uma mãe de pele escura? (ANZALDÚA, 2007, p. 100. Grifo da autora).

No processo de re-contextualização, a nova mestiça de Anzaldúa percebe que a subjugação feminina ocorre pela perpetuação e valorização dos modelos culturais impostos pela cultura falocêntrica. Modelos que incitam a mulher à obediência masculina, à pureza, à docilidade e à submissão tal como prediz a religião católica na figura da Virgem Maria (ou a Virgem de Guadalupe, no México). Modelo cultural que, seguindo o padrão mexicano, encoraja os homens a baterem nas mulheres se elas forem desobedientes ou rebeldes; se não desempenharem bem as tarefas domésticas, se não servirem bem aos maridos e filhos ou então, discrimina-as por não se manterem virgens até o casamento. Quaisquer desvios a essas normas e a mulher pode ser publicamente envergonhada, insultada ou até excluída da comunidade. 
Pontos de Interrogação, v. 3, n. 1, jan./jul. 2013

Revista do Programa de Pós-Graduação em Crítica Cultural

Universidade do Estado da Bahia (UNEB), Campus II - Alagoinhas - BA

Para que o sujeito feminino chicano liberte-se desses grilhões patriarcais que moldam o seu comportamento, Anzaldúa propõe que a mestiça se desprenda dos códigos culturais que lhe foram ensinados desde criança e dos valores impregnados nele - seu legado histórico patriarcal - e reconfigure o passado, de maneira a não compactuar com os códigos culturais masculinos que diminuem o papel da chicana na sociedade. Para tanto reafirma sua herança pré-colombiana e ressignifica a figura mítica de A Chorona (La Llorona) presente nessa cultura e que se opõe à figura da Virgem de Guadalupe:

A Chorona para mim [é] uma das figuras mais importantes da minha vida; mas não A Chorona tradicional, mas uma que eu revisei [...] e no lugar de ser uma mãe sofredora e passiva, surge a figura de uma mulher que tem voz e que levanta sua voz aos céus, e que tem boca e essa boca é sua, e que é uma mulher que nunca foi boa, porque o patriarcado quer as mulheres boas, decentes que cuidando do marido e dos filhos, então aqui surge A Chorona, má porque matou os seus filhos. Não é boa mãe, boa amante, boa esposa ${ }^{9}$ (JOYSMITH, 2004, p. 227).

Para renovar esse passado, há a necessidade de reescrever um novo paradigma cultural no presente que adote características tanto da cultura opressora quanto da cultura oprimida e forme uma terceira cultura, na qual será capaz de aflorar a nova consciência mestiça, mesmo que essa não esteja de acordo com os padrões esperados pela sociedade hegemônica. Entretanto, se a situação das mulheres mestiças é complicada, Anzaldúa ressalta que a situação das mestiças lésbicas (como ela própria) — as queers — é ainda mais problemática. Elas representam a terceira margem; ou seja, uma escolha aquém da organização de oposições binárias de gênero existente na sociedade falocêntrica. A voz diferente da lésbica, a "outra” mesmo dentro do feminino, incomoda tanto o poder hegemônico patriarcal quanto o feminino, porque se expressa a partir da periferia do poder e representa outra possibilidade de vir a ser. Por isso, ela é discriminada em sua própria cultura. Essa atitude discriminatória para a autora baseia-se no medo: a mestiça lésbica é vista como uma ameaça, porque questiona os pilares da ordem patriarcal, e desafia os padrões sexuais da sociedade e da cultura hegemônica:

\footnotetext{
Assombra pensar que ficamos nesse poço escuro onde o mundo confina as lésbicas. Assombra pensar que fechamos, como feministas e lésbicas, nossos corações aos homens, aos nossos irmãos - os homossexuais - sem herança e marginais como nós. Por serem os/as maiores cruzadores/as de fronteiras, os/as homossexuais têm laços fortes com os queer brancos, negros, asiáticos, ameríndios, latinos, e com os queers na Itália, na Austrália, e no resto do planeta. (ANZALDÚA, 2007, p. 106. Grifo da autora).
}

9 Tradução livre da autora do trabalho. 
Para Anzaldúa, a mestiça deve construir sua nova consciência sob essas diferenças. Uma consciência que englobe, tal qual o seu lugar de enunciação - a fronteira, os diversos elementos díspares que formam a sua identidade. Elementos que se imbriquem para formar uma identidade porosa, flexível, mutável e maleável, sem limitações fixas. Uma identidade fronteiriça contra-hegemônica abarcadora capaz de incluir ao invés de excluir e que compreenda os opostos existentes nas margens das duas culturas com as quais convive. Identidade capaz de atravessar as fronteiras na trajetória de um espaço híbrido, em busca da terceira margem. Sem medo de chegar a um território completamente novo. Consciente de que através da aceitação das diferenças, a mulher mestiça e queer se completa e existe como gênero, etnia, raça e opção sexual. Trata-se, afinal, do reconhecimento dos entre-lugares como parte do caleidoscópico que forma a identidade do sujeito contemporâneo.

\title{
4 UM NOVO ESPAÇO
}

A construção da identidade fronteiriça contra-hegemônica da mestiça perpassa pela construção de uma linguagem marcada pela classe e pela etnia. Uma linguagem própria dos chicanos que desconstrua as práticas discursivas oriundas da cultura hegemônica:

\begin{abstract}
Quando os mexicano-americanos querem definir o que é a cultura chicana, da diferença da mexicana, a linguagem tem muito que ver: o "Tex-mex", "spanglish”, chicano, assim como a cultura popular, porque o que lemos, o que vemos na televisão, no cinema, nos lugares onde nos divertimos, são mundos nos quais se misturam o mexicano e o americano, a cultura dominante ${ }^{10}$ (JOYSMITH, 2004, p. 223).
\end{abstract}

Em Borderlands/La Frontera, Anzaldúa problematiza as relações de poder inerentes às práticas discursivas em situações de opressão social e entrecruzamento de culturas e mostra como elas são capazes de construir uma subjetividade para o sujeito subalterno. A problematização do discurso como representação do poder está presente em toda a obra através do uso concomitante do inglês, do espanhol e do spanglish. Os jogos de poder construídos pela autora ficam evidentes no uso do itálico para os termos em espanhol e em spanglish, revelando que não pertencem à língua utilizada pela cultura hegemônica.

\footnotetext{
10 Tradução livre da autora do trabalho.
} 
Pontos de Interrogação, v. 3, n. 1, jan./jul. 2013

Revista do Programa de Pós-Graduação em Crítica Cultural

Universidade do Estado da Bahia (UNEB), Campus II - Alagoinhas - BA

Em uma linguagem em forma de testemunho pessoal, a autora apresenta exemplos de como a cultura hegemônica, tanto a estadunidense quanto a mexicana, tentou (mas não conseguiu) domar a sua maneira de usar a língua própria da fronteira: o spanglish. Também aborda como a representação do feminino e especificamente da chicana por esse discurso hegemônico masculino encobre e/ou apaga a verdadeira identidade da mestiça que aflora na fronteira México-Estados Unidos. Seu texto desvela a linguagem como centro e local para os jogos de poder da cultura hegemônica, nos quais intervêm a história, a política, a nacionalidade e a subjetividade. Por isso, a linguagem ocupa um lugar preponderante na reconfiguração da nova identidade do sujeito mestiço da fronteira, que não só deseja transcender os limites étnicos, mas também eliminar as desigualdades de poder que estão presentes nas práticas discursivas:

\footnotetext{
A primeira vez que ouvi duas mulheres, uma porto-riquenha e uma cubana, dizerem a palavra "nosotras", fiquei chocada. Eu nem sabia que essa palavra existia. Chicanas usam "nosotros" sejamos machos ou fêmeas. Somos privadas do nosso feminino pelo plural masculino. A linguagem é um discurso masculino (ANZALDÚA, 2007, p. 76. Grifo da autora).
}

A força dessas questões é corroborada pela necessidade de uma língua identificadora da etnia que nasce e vive nesse espaço híbrido. Em uma sociedade de desigualdades persistentes, na qual o conhecimento não pode mais ser conceituado em termos neutros, mas como inerentemente imbricados em relações de poder, a identidade de um povo se dá pela língua. Então, a consciência chicana perpassa também pela construção de um idioma que a identifique. A língua se torna para o chicano um disputado terreno de formação de identidade:

O espanhol chicano surgiu da necessidade de os chicanos se identificarem como um povo distinto. Nós precisávamos de uma língua com a qual pudéssemos nos comunicar uns com os outros, uma língua secreta. Para alguns de nós, a língua é uma terra natal mais próxima do que o sudoeste pois muitos chicanos vivem hoje no meio-oeste e no leste (ANZALDÚA, 2007, p. 77).

Se a língua é uma das formas de constituição da nacionalidade, então o uso de uma língua própria diferencia os chicanos das demais etnias hispânicas existentes nos Estados Unidos. É uma maneira de não ser unificado pela cultura branca hegemônica - a angloamericana - que utiliza as práticas discursivas para fazer prevalecer a sua vontade e moldar, segundo os seus próprios padrões, o sujeito chicano ou inclusive, emudecê-lo. A narrativa evidencia que o apoderamento da linguagem dos grupos minoritários — nesse caso os chicanos — é uma das maneiras utilizadas pelo poder hegemônico para subjugar e silenciar os oprimidos: “Ataques à forma de expressão de alguém com o intento de censurar são violações 
à Primeira Emenda. O Gringo com cara de inocente nos arrancou a língua. Línguas selvagens não podem ser domadas, elas podem apenas ser decepadas” (ANZALDÚA, 2007, p. 76. Grifo da autora).

Contudo, tal questionamento não perpassa somente pelo discurso do opressor branco. A crítica de Anzaldúa se estende ao mexicano que também oprime a cultura chicana e utiliza os mesmos mecanismos de poder do opressor branco para "unificar” a língua e eliminar, dessa forma, a voz diferente: "Mesmo nossa própria gente, outros falantes do espanhol querem colocar cadeados em nossas bocas. Eles nos conteriam com seu montão de regras de academia” (ANZALDÚA, 2007, p. 76. Grifo da autora).

Sob essa perspectiva, a enunciadora rejeita tanto o idioma espanhol (que simboliza a imposição machista mexicana à cultura chicana) quanto o idioma inglês (imposto ao(à) chicano(a) através da escolarização) e defende a adoção, pela nova mestiça, de um idioma que a autorrepresente, o Tex-Mex ${ }^{11}$ ou spanglish: “Tex-Mex, ou Spanglish, é mais natural para mim. Eu posso mudar do inglês para o espanhol na mesma sentença ou na mesma palavra. Com minha irmã e meu irmão Nune e com contemporâneos chicanos tejanos eu falo Tex-Mex" (ANZALDÚA, 2007, p. 77. Grifo da autora). Não deseja uma língua imposta, incapaz de representar o seu universo, mas uma língua nascida no seio da cultura híbrida em que vive. Contudo, a voz enunciadora não relaciona apenas essas três línguas. Ela apresenta, de maneira hierarquizada, os outros idiomas falados pelos sujeitos fronteiriços. Entretanto, a hierarquização é feita segundo a importância que a língua tem dentro da cultura branca hegemônica:

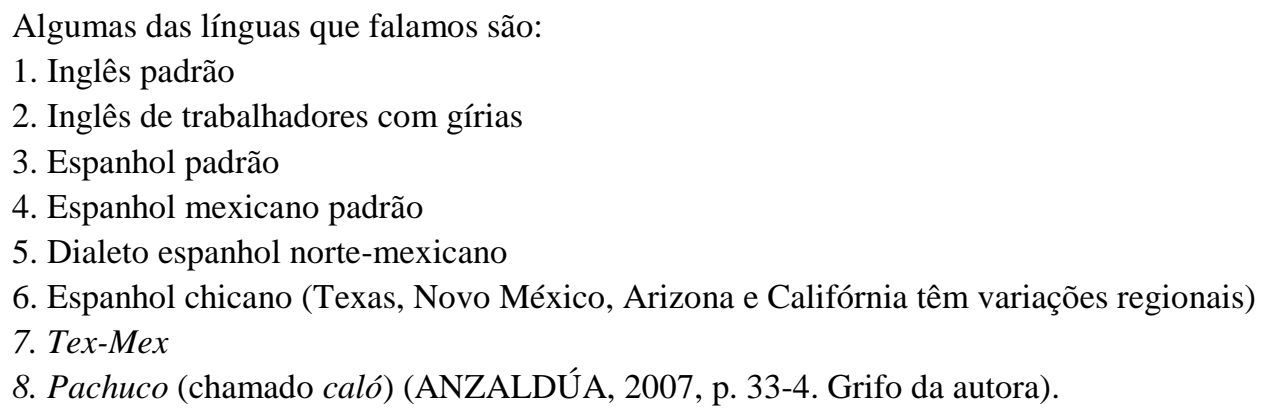

A partir dessa hierarquização, a enunciadora discute as relações de poder suscitadas pelo uso dessas línguas pelos sujeitos mestiços da fronteira. Apodera-se dos idiomas considera-

11 Tex-Mex: expressão adjetiva para tratar de cultura, comida e variante linguística originadas no Texas, fronteira com o México. 
Pontos de Interrogação, v. 3, n. 1, jan./jul. 2013

Revista do Programa de Pós-Graduação em Crítica Cultural

Universidade do Estado da Bahia (UNEB), Campus II - Alagoinhas - BA

dos “legítimos” pela cultura hegemônica e, portanto, circunscritos a um círculo de poder para, em seguida, recontextualizá-los conforme a sua preferência de uso e, novamente hierarquizálos. Essa nova hierarquização reflete a sua identidade chicana e, por isso, não coincide com a feita pela cultura dominante. Propõe um novo paradigma de linguagem, mais conforme a sua consciência mestiça. O apoderar-se da linguagem híbrida, que transita no entre-lugar da fronteira, é para Anzaldúa uma arma poderosa, pois lhe permite reivindicar uma identidade mestiça, consciente de estar no entre-lugar, de não pertencer nem à cultura anglo-americana e tampouco à mexicana, mas à cultura híbrida que faz parte da fronteira.

Dessa forma, a dualidade linguística marcada no próprio título do livro, através do sinal gráfico da barra (/) se resolve ao refletir sobre a linguagem: seu espaço não é o mexicano e tampouco o estadunidense, é o da fronteira. Esse é o espaço próprio da mestiça. A identidade étnica resultante desse espaço se manifesta, efetivamente, na língua. A língua lhe permite reterritorializar-se. É sua pátria, seu local de residência. De ser “deslinguado”12 e, portanto, desterritorializado, passa a sujeito com poder, pois possui uma língua própria capaz de representá-lo em um espaço definido. É necessário para ela ressaltar a existência de um idioma próprio, de uso do chicano para poder marcar a sua essência cultural. Desse modo, o sentimento nacionalista de orgulho de um lugar se desloca para a plena identificação da mestiça com a sua língua:

\footnotetext{
Assim, se você quer mesmo me ferir, fale mal da minha língua. A identidade étnica e a identidade linguística são unha e carne - eu sou minha língua. Eu não posso ter orgulho de mim mesma até que possa ter orgulho da minha língua. Até que eu possa aceitar como legítimas o espanhol chicano texano, o Tex-Mex e todas as outras línguas que falo, eu não posso aceitar a minha própria legitimidade. Até que eu esteja livre para escrever de maneira bilíngue e permutar idiomas sem ter sempre que traduzir, enquanto eu ainda tiver que falar inglês ou espanhol quando preferiria falar Spanglish, e enquanto eu tiver que me acomodar aos falantes de inglês ao invés deles se acomodarem a mim, minha língua será ilegítima. Eu não vou mais sentir vergonha de existir. Eu vou ter minha voz: indígena, espanhola, branca. Eu vou ter minha língua de serpente — minha voz de mulher, minha voz sexual, minha voz de poeta. Eu vou superar a tradição de silêncio (ANZALDÚA, 2007, p. 81. Grifo da autora).
}

12 “Deslinguadas. Somos os do espanhol deficiente. Somos seu pesadelo linguístico, sua aberração linguística, sua mestizagem linguística, o sujeito da sua burla. Porque falamos com línguas de fogo nós somos culturalmente crucificados. Racialmente, culturalmente e linguisticamente somos órfãos — nós falamos uma língua órfã” (ANZALDÚA, 2007, p. 80. Grifo da autora). 


\section{CONCLUSÕES}

Através da ressignificação dos elementos de sua cultura hispânica e pré-hispânica mesclados aos elementos da cultura dominante anglo-americana, da qual também faz parte, a autora mostra a existência de outra, a chicana. Uma cultura de fronteira, considerada inferior, marginal e exótica pela dominante, enredada nos pré-julgamentos e nos preconceitos enraizados pela visão do “outro” branco, de classe média, americano e/ou mexicano. Anzaldúa descreve essa cultura fronteiriça sem depreciar os elementos existentes nela. Sabe que rejeitar o hibridismo cultural e a miscigenação é rejeitar o seu próprio ser. Assim não hierarquiza as culturas ou as etnias necessárias para formar a subjetividade chicana, como o faz a cultura dominante que classifica as culturas nas oposições binárias: centrais/periféricas ou dominantes /marginalizadas.

Em seu texto, reconhece a importância da interação de todas as culturas existentes nesse espaço físico, sem menosprezá-las ou quitar-lhes a devida importância para a construção identitária do sujeito que vive em um constante ir-e-vir na fronteira. Sujeito que não está nem em um lugar nem em outro, mas no "entre-lugar”, no "não-lugar” em que as identidades são fragmentadas e estão em constante deslocamento por causa das múltiplas identidades — impostas ou escolhidas - provenientes das conquistas e dos contatos da cultura. Essas múltiplas identidades fazem do sujeito chicano um ser menosprezado pelo “outro" hegemônico, sem reflexo no espelho dessa outredade e, portanto, perdido em si mesmo.

Anzaldúa, sabedora dessa fragmentação, recolhe os estilhaços espalhados dessa subjetividade e os junta para formar uma nova noção de identidade e de história. Uma identidade que se orgulhe de ser o que é: mestiça. Entretanto, sua conquista vai além: resgata a identidade chicana, relacionando-a com a questão do gênero. A consciência mestiça articulada por Anzaldúa provém do feminismo e do desejo de superar a amarras da opressão. Não deseja recuperar somente a identidade mestiça, mas também a identidade do ser feminino, chicano e homossexual. Deseja que a mestiça tenha orgulho de sua identidade, sem sentir-se menosprezada em suas diferenças.

Contudo, é consciente de que as práticas discursivas organizam e representam a realidade e que a mestiça chicana encontra-se no centro dos jogos de poder oriundos dessas práticas. Por isso, para a autora, a questão da representação é vista como central na busca pelo poder 
político e cultural da mestiça. É necessário que a mestiça se apodere da linguagem para ser capaz de representar a si mesma e a sua gente. Só assim será capaz de minorar ou até mesmo eliminar as construções discursivas do sujeito feminino chicano feitas pelo poder hegemônico.

Apoderar-se da linguagem significa incorporar o spanglish como o código linguístico que a representa no grupo social. A língua chicana utilizada pela mestiça não é incorreta, como afirma a cultura dominante, mas uma língua viva que representa o seu modo de ser, seus pensamentos, sentimentos; além de ajudar a desconstruir as relações de poder ordenadas pela linguagem da cultura hegemônica. Através dessa língua híbrida, de características chicana, mexicana e texana, a nova identidade mestiça e a consciência dessa nova identidade podem aflorar. Com o poder que lhe dá a posse de uma língua que o represente, sem os subterfúgios da linguagem do poder dominante, o sujeito feminino chicano que nasce na fronteira pode chegar a ser a nova mestiça desejada por Anzaldúa: sujeito consciente de sua hibridez, de sua mestiçagem, mas sem a vergonha de assumir essa identidade.

Assim, a consciência mestiça, pregoada pela autora em seu texto, surge como uma forma de abrir espaços para a compreensão das relações de sentidos que se reconstroem na heterogeneidade. Sua obra é um ponto de resistência cultural que parte do marginal à nova consciência mestiça, com o objetivo de valorizar a sua cultura e compreender os seres ex-cêntricos que escrevem sua memória histórica para se tornarem sujeitos com voz e poder dentro da sociedade. É a conscientização de que como mulher, chicana e homossexual fala do outro lugar da cultura, o marginal, mas ainda assim, é capaz de desconstruir as relações de poder tecidas sobre si pela cultura dominante.

\section{REFERÊNCIAS}

ANZALDÚA, Gloria. Borderlands/La frontera. The new mestiza. 3. ed. Aunt Lute Books: San Francisco, Ca, 2007.

ANZALDÚA, Gloria. Falando em línguas: uma carta para as mulheres escritoras do terceiro mundo. Trad. Édna de Marco. Revista Estudos Feministas. Florianópolis: UFSC, v. 8, n. 1, p. 229-36, 2000.

BHABHA, Homi K. O local da cultura. Trad. Myriam Ávila et al. 4. reimp. Belo Horizonte: Ed. UFMG, 2007. 
BURKE, Peter. Hibridismo cultural. Trad. Leila Souza Mendes. 3. reimp. São Leopoldo: Ed. Unisinos, 2010.

BUTLER, Judith. Problemas de gênero: feminismo e subversão da identidade. Trad. Renato Aguiar. 3. ed. Rio de Janeiro: Civilização Brasileira, 2010.

CHANTER, Tina. Gênero: conceitos-chaves em filosofia. Trad. Vinicius Figueira, Porto Alegre: Artmed, 2011.

CORBATTA, Jorgelina. Feminismo y escritura femenina en Latinoamérica. Corregidor: Buenos Aires, 2002.

COSTA, Claudia de Lima; ÁVILA, Eliana. Gloria Anzaldúa, a consciência mestiça e o "feminismo da diferença”. Revista Estudos Feministas. Florianópolis: UFSC, v. 13, n. 3, p. 691703, set./dez. 2005.

EBERT, Teresa. Femenismo y postmodernismo de la resistencia. Diferenciadentro/Diferencia-entre. In: CARBONELL, Neus; TORRAS, Meri. (Comp. e bibliog.). Feminismo literarios. Madrid: Arcos Libros, 1999, p. 199-232.

FIGUEIREDO, Eurídice; NORONHA, Jovita Maria. Identidade nacional e identidade cultural. In: FIGUEIREDO, Eurídice (Org.). Conceitos de literatura e cultura. Juiz de Fora: UFJF, 2005, p. 189-205.

HALL, Stuart. A identidade cultural na pós-modernidade. Trad. Tomaz Tadeu da Silva e Guacira Lopes Louro. 10. ed. Rio de Janeiro: DP\&A, 2005.

JOYSMITH, Claire. Ya se me quitó la vergüenza y la cobardía. Una plática con Gloria Anzaldúa. In: COSTA, Claudia de Lima; SCHMIDT, Simone Pereira (Org.). Poéticas e políticas feministas. Santa Catarina: Ed. Mulheres, 2004, p. 219-231.

SKAR, Stacey Alba D. Voces híbridas. La literatura de chicanas y latinas en Estados Unidos. Santiago: RIL Editores, 2001.

SORJ, Bila. O feminismo na encruzilhada da modernidade e pós-modernidade. In: COSTA, Albertina, BRUSCHINI, Cristina (Org.). Uma questão de gênero. Rio de Janeiro: Rosa dos tempos; São Paulo: Fundação Carlos Chagas, 1992, p. 8-20.

TORRES, Sônia. Nosotros in USA. Literatura, etnografia e geografias de resistência. Rio de Janeiro: J. Zahar, 2001.

VELASCO MARÍN, María Adriana. La crítica feminista, el dedo en la llaga o el cuestionamiento al canon literario. In: GUARDIA, Sara Beatriz (Ed.). Mujeres que escriben en América Latina. Peru: Centro de Estudios de la Mujer en la Historia de América Latina (CEMHAL), 2007, p. 551-62.

Recebido em: 29 de julho de 2013.

Aceito em: 30 de setembro de 2013. 